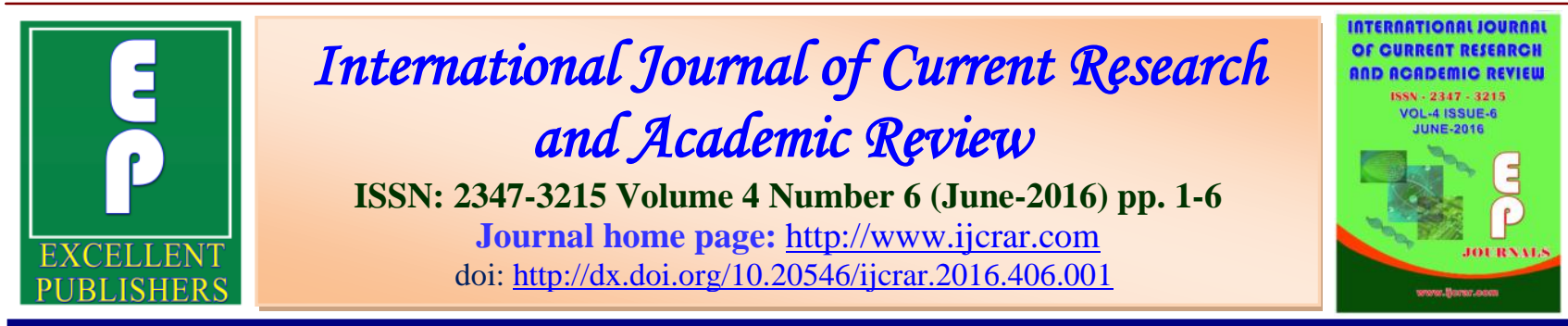

\title{
Practical effect of walking on the Hemodynamic profile of olderly people in
} Congo-Brazzaville

\section{Moussouami Simplice Innocent ${ }^{1 *}$, Bazaba Kayilou Jean Michel ${ }^{1,3}$, Bouhika Eddie Janvier $^{1}$, Nsompi Florent ${ }^{1}$, Nimi Fresnay Urgel ${ }^{1}$, Mbemba François ${ }^{1}$ and P. Senga ${ }^{2}$}

${ }^{1}$ Laboratoire de Physiologie de 1'Effort, de Biomécanique et Nutrition, Institut Supérieur d'Education Physique et Sportive, Université Marien NGOUABI, Brazzaville, Congo

${ }^{2}$ Service de pédiatrie-nourrissions, centre hospitalier universitaire (CHU), Brazzaville,

${ }^{3}$ Centre de Rééducation et de Revalidation cardiovasculaire (Fitness)

*Corresponding author

\section{KEYWORDS}

Elderly, cardiovascular values, physical activity

\section{A B S S T R A C $\mathbf{C}$}

To assess the impact of physical activity on administrative environment on the health of older people in Congo Brazzaville. This longitudinal study of comparative type was conducted on 60 subjects divided into two groups: 30 walkers (including 15 women and 15 men of the club of walkers Diata district of the city of Brazzaville Congo) and 30 sedentary. Their average age was $51.00 \pm 6.36$ years respectively for men and $52.86 \pm 6.03$ years for women. All subjects had a practice of duration of physical activity and sport (power walking) at least one (1) year s with two (2) sessions per week. The biometric parameters (height, weight, body mass index, the adbomen-hip ratio), clinical (heart rate and blood pressure) were evaluated. The values were compared between the two groups: practicing physical and sedentary activity. Reduction in weight in patients practicing physical activity was observed compared to sedentary with values of $70.13 \pm 6.38 \mathrm{~kg}$ versus $72.93 \pm 7.67 \mathrm{~kg}$ for men and $70.93 \pm 11.29 \mathrm{~kg}$ vs $78.4 \pm 16.49 \mathrm{~kg}$ for women, the abdomen-hip ratio was not significant between groups. Similarly, a decrease in blood pressure and resting heart rate was observed in patients (men and women) practicing walking compared to sedentary subjects with values of blood pressure (systolic and diastolic) from $121.33 \pm 10.72$ versus $133,26 \mathrm{mmHg} ; 86.53 \pm$ 12.79 versus $87.46 \pm 13.61 \mathrm{mmHg}$ and heart rate $78.20 \pm 11.87$ versus 73.86 $\pm 8.62 \mathrm{bpm}$ for men. As the values of blood pressure (systolic and diastolic blood pressure) of $120.20 \pm 9.84$ vs $130.46 \pm 15.17 \mathrm{mmHg}$ for systolic blood pressure; $78.80 \pm 9.34$ versus $90.60 \pm 16.17 \mathrm{mmHg}$ diastolic blood pressure and heart rate $80.13 \pm 12.60$ versus $81.93 \pm 10.90 \mathrm{bpm}$ in women. A rational and regular practice of running in the elderly has beneficial health effects: body composition and its hemodynamic profile. 


\section{Introduction}

The advancing age induces several structural and functional changes in the cardiovascular system (Lakatta, 2003). In fact, regular exercise has undeniable beneficial effects for health in general and the cardiovascular system in particular. However, the growing number of older people worldwide is a major public health challenge to improve health outcomes in populations âgéesen turning to therapy exercise (Thompson et al., 2001). A particular concern in the elderly is the development of frailty associated with cardiovascular diseases. Moreover, advancing age is accompanied by a deterioration in the ability to long-term exercise (aerobic system) and the ability to exercise at high intensity (anaerobic pathway) (Astrand et al., 1973).

Physical activity contributes significantly to cardiovascular health. Primary and secondary preventive effects are generally obtained through regular endurance sports at a moderate intensity (Matthias Wilhelm, 2011). Very intense endurance sports and very prolonged reactions lead to structural adaptation of the heart and an increase in performance. Physical activity prevents a number of deleterious processes related to aging (Blain et al., 2000). It reduces the decline linked to advancing age of physical fitness that is limited by the reduction of the maximum heart rate, and reduced the incidence of vascular disease by preventing and reducing the effect of vascular risk factors.

However, previous studies have shown that this gradual and steady decline of age in progress can be minimized by training. Aerobic training is an essential component of cardiac rehabilitation programs, and had been associated with improved cardiovascular performance submaximal and maximal, even in the elderly. Even a training program of moderate intensity exercise, if followed regularly, with favorable effects on several health outcomes, if tailored to the clinical and functional status or preference of the elderly patient (Vigorito et al., 2003).

In today's society, older people with cardiovascular problems (blood pressure, overweight) advanced in years focuses on pharmaceutical products for survival. Congo Brazzaville and in other countries of Black Africa, the practice of physical activity maintenance in the elderly is far less known.

This study aims to assess the effects of walking on cardiovascular parameters of the Congolese elderly.

\section{Material and Methods}

This study, comparative longitudinalede kind took place in Brazzaville (Congo) to the stadium Alphonse Massamba DEBATE center for rehabilitation and cardiovascular rehabilitation (Fitness) from 15 February to 4 April 2015. It involved 30 subjects practicing physical activity and regular sports and 30 sedentary healthy subjects. Their age was between 45 and 60 years with an average age of $54.62 \pm 0.7$ years for both sexes (male and female). The target population consisted of government officials (state) of Congo Brazzaville. Only individuals with a term of one (1) year of participation in physical activity and sport, without pathology; and the subjects practicing any sport and physical activity (sedentary) in good health were the subject of this study. Inclusion criteria were: age over 45 and under 60 years old, have high blood pressure not exceeding $150 \mathrm{mmHg}$. Exclusion criteria were: be aged under 45 and over 60 , have critical values of blood pressure. The objectives of the study were 


\section{Int.J.Curr.Res.Aca.Rev.2016; 4(6): 1-6}

explained to each subject and the subsequent use of the data.

\section{Experimental Procedure}

Measurements of the size (measured at 0.5 $\mathrm{cm}$ ) Weight (estimated at $0.1 \mathrm{Kg}$ close) were performed before the study. Body mass index (BMI) was calculated by the ratio (weight (kg)) / (Height (m)) 2. The hip circumference and abdomen were measured using a meter ribbon.

The heart rate (HR) in beats per minute (bpm), was measured using a portable heart rate monitor (Polar Trainer more $\times \mathrm{TM}$ ) storing beats every 5 seconds. The system corresponding to a sensor placed around the torso by means of a belt and a watch -shaped receiver fixed around the wrist. Finally, pression artérielle was measured in the right arm with a sphygmomanometer Digital Display (pbiodex, St Paul, Minnesota, USA). All values were obtained at rest

\section{Variables Studied}

The variables studied in this work were : weight, body mass index , the abdomen - hip ratio, heart rate, systolic blood pressure (No) and diastolic blood pressure (Pad).

\section{Statistical Analysis}

All statistical analyzes as described below were performed using SPSS software (version 21, SAS Institute, Cary, NC). Means and standard deviations were used for all variables of the study. To determine whether the practice of walking had an effect on the anthropological parameters and cardiovascular profile, we had to make a ttest for dependent sample to determine differences between groups. The confidence level was set at $95 \%$ and accounted for $5 \%$ significance level for all statistical tests ( $p$ $<0.05)$

\section{Results and Discussion}

Anthropometric measurements in age, height and weight of men practicing physical activity and sedentary were $48.33 \pm$ 2.89 years, respectively, versus $51.00 \pm 6.36$ years; $1.71 \pm 0.06 \mathrm{~m}$ versus $1.71 \pm 0.09 \mathrm{~m}$ and $70.13 \pm 6.38 \mathrm{~kg}$ versus $72.93 \pm 7.67 \mathrm{~kg}$ and that of practitioners and non practitioners women were $52.86 \pm 6.03$ years vs $51.53 \pm 9.15$ years, $1.63 \pm 0.08$ vs $1.54 \pm 0.43 \mathrm{~m}$ and $70.93 \mathrm{~m} \pm 11.29 \mathrm{~kg}$ vs $78.4 \pm 16.49 \mathrm{~kg}$ (table 2 ). These variables studied, no significant differences were observed among practicing men and women walking compared to sedentary.

The values of systolic blood pressure were $121.33 \pm 10.72$ versus $133.26 \mathrm{mmHg}$ while those in diastolic blood pressure were 86.53 \pm 12.79 versus $87.46 \pm 13.61 \mathrm{mmHg}$ and for the heart rate $78.20 \pm 11.87$ versus $73.86 \pm$ $8,62 \mathrm{bpm}$. For men or not practicing sport and physical activity.

The values of systolic blood pressure were $120.20 \pm 9.84$ vs $130.46 \pm 15.17 \mathrm{mmHg}$; diastolic blood pressure $78.80 \pm 9.34$ versus $90.60 \pm 16.17 \mathrm{mmHg}$ and the heart rate $80.13 \pm 12.60$ versus $81.93 \pm 10.90 \mathrm{bpm}$ for women practicing physical activity and athletic and sedentary.

\section{Characteristics of Subjects}

The present study included men and women practicing sport and physical activity (walking) and sedentary whose average weight was $70.13 \pm 6.38 \mathrm{~kg}$, respectively vs. $72.93 \pm 7.67 \mathrm{~kg}$ and $7093 \pm 11.29 \mathrm{~kg}$ vs $78.4 \pm 16.49 \mathrm{~kg}$. A significant difference in weight was observed between men and women practicing physical activity and 
Int.J.Curr.Res.Aca.Rev.2016; 4(6): 1-6

sedentary. It is often shown that regular physical activity has an effect on body weight (Casa et al., 2000). In view of these results, it is therefore reasonable to think that men and women practicing sport embedded in this sample have a low training level.

\section{Cardiovascular Profile Settings}

Men and women practicing sport and physical activity (walking) who participated in this study saw their performance in systolic blood pressure and diastolic blood pressure decrease compared to sedentary. Given these results, several studies have shown the beneficial effect of the practice of physical activity on systolic blood pressure (SBP) and diastolic blood pressure (DBP). These researchers believe that blood pressure during physical and sports activities will depend on the characteristics of the activity (Mitchell et al., 1994). For an endurance activity (effort "dynamic"), arteriolar vasodilation during the warm-up will decrease peripheral resistance and contribute to a decline in PAD, the rise in blood pressure during the following year will be moderate and progressive for PAS, and discrete or no to the PAD. At the end of the year, there is a post-exercise hypotension (HPE) (Mitchell et al., 2013), which continues on average up to $22 \mathrm{~h}$ after the exercise session. It is about $8 / 9 \mathrm{~mm} \mathrm{Hg}$ (SBP / DBP) in normo tense, $14 / 9 \mathrm{mmHg}$ in pre-hypertensive and $10 / 7 \mathrm{mmHg}$ in hypertensive patients treated. (MacDonald, 2002) The specific benefit of the HPE is unknown; its duration, the same as a sustained-release drug, contribute to chronic hypotensive effect in case of repetition of the sessions. (Hecksteden et al., 2013) Similarly structured program of physical activity reduces blood pressure in hypertensive patients, an average of 11 $\mathrm{mmHg}$ for systolic blood pressure and 8 $\mathrm{mmHg}$ for diastolic pressure. It allows you to delay, or even render useless, drug treatment of hypertension in newly diagnosed.

Genetic and environmental factors may influence changes in arterial blood pressure during a physical training program . (Rice $e t$ al., 2002) This dimension is poorly understood because little studied. However, it is noteworthy that the hereditary component in the adaptation of blood pressure in a 20 -week endurance training appeared as low systolic pressure and heart rate $(17-30 \%$ reduction) and negligible diastolic pressure. In short, the practice of physical activity is now considered an essential part of the care of patients with hypertension .

Table.1 Anthropometric Measurements

\begin{tabular}{|ccccc|}
\hline Variables & \multicolumn{2}{c}{ Men $(\mathrm{n}=30)$} & \multicolumn{2}{c|}{ Women $(\mathrm{n}=30)$} \\
& $\begin{array}{c}\text { Hom_Prat } \\
(\mathrm{n}=15)\end{array}$ & $\begin{array}{c}\text { Hom_Prat pas } \\
(\mathrm{n}=15)\end{array}$ & $\begin{array}{c}\text { Fem_Prat } \\
(\mathrm{n}=15)\end{array}$ & $\begin{array}{c}\text { Fem_Prat pas } \\
(\mathrm{n}=15)\end{array}$ \\
\hline Age $(\mathrm{an})$ & $48,33 \pm 2,89$ & $51,00 \pm 6,36$ & $52,86 \pm 6,03$ & $51,53 \pm 9,15$ \\
\hline Cut $(\mathrm{m})$ & $1,71 \pm 0,06$ & $1,71 \pm 0,09$ & $1,63 \pm 0,08$ & $1,54 \pm 0,43$ \\
\hline Weight $(\mathrm{kg})$ & $70,13 \pm 6,38$ & $72,93 \pm 7,67$ & $70,93 \pm 11,29$ & $78,4 \pm 16,49$ \\
IMC $(\mathrm{kg} / \mathrm{m} 2)$ & $25,7 \pm 3,5$ & $26,30 \pm 4,6$ & $26,25 \pm 3,2$ & $27,14 \pm 5,18$ \\
RAH & $1,1 \pm 0,1$ & $1,3 \pm 0,3$ & $1,5 \pm 0,2$ & $1,7 \pm 0,4$ \\
\hline
\end{tabular}

Hom_Prat : Men practicing sport; Hom_Prat not : Men do not practice sport; Fem_Prat : Women practicing sports; Fem_Prat not : Women not practicing sport, BMI : Body Mass Index , RAH : Abdomen - hip Report 
Int.J.Curr.Res.Aca.Rev.2016; 4(6): 1-6

Table.2 Change parameters of the cardiovascular profile

\begin{tabular}{|c|c|c|c|c|}
\hline \multirow[t]{2}{*}{ Variables } & \multicolumn{2}{|c|}{$\operatorname{Men}(n=30)$} & \multicolumn{2}{|c|}{ Women $(n=30)$} \\
\hline & $\begin{array}{c}\text { Hom_Prat } \\
(\mathrm{n}=15)\end{array}$ & $\begin{array}{c}\text { Hom_Prat pas } \\
(\mathrm{n}=15)\end{array}$ & $\begin{array}{c}\text { Fem_Prat } \\
(\mathrm{n}=15)\end{array}$ & $\begin{array}{c}\text { Fem_Prat pas } \\
(\mathrm{n}=15)\end{array}$ \\
\hline PAS (mmHg) & $121,33 \pm 10,72 *$ & $133,26 \pm 13,61$ & $120,20 \pm 9,84^{*}$ & $130,46 \pm 15,17$ \\
\hline PAD (mmHg) & $86,53 \pm 12,79$ & $87,46 \pm 13,99$ & $78,80 \pm 9,34^{*}$ & $90,60 \pm 16,76$ \\
\hline FC (bpm) & $78,20 \pm 11,87$ & $73,86 \pm 8,62$ & $82,13 \pm 12,60$ & $80,93 \pm 10,90$ \\
\hline
\end{tabular}

We can say that the results obtained in this study on cardiovascular values (SBP and DBP) are consistent with those of the literature and reflect the practice of physical activity (walking).

The values of the resting heart rate showed a non-significant difference either in men or women $(\mathrm{p}=0.263$ for men and $\mathrm{p}=$ 0.679 for women). Although the values observed in men and women are in the standards, it allows to say that the practice of physical activity (walking) to a nonsignificant effect on heart rate of the subjects of the study. Comparative previous studies of heart rates of athletes over 55 years and sportsmen of 15-25 years have shown that heart rate was the same at rest. In addition, they increase during exercise and then three minutes after the effort they descend almost to the value of rest and during exercise, the mean heart rate of athletes of these two age groups do not exceed 120 beats / min (Manon et al., 2008-2009). Moreover by comparing heart rate of athletes and sedentary, they find that the average heart rate of sedentary is always higher than that of subjects trained at rest for 3 minutes after exercise. Moreover, during exercise, average heart rate exceeds 120 beats sedentary / min can reach 130 beats / min. Our results corroborate those in the literature with weak Manon et al values. (2009), this is due to the intensity, volume of work and the tempsde practice of physical activity and sport.

\section{Conclusion}

This study's main objective was to evaluate the effect of the practice of walking on the cardiovascular profile of people aged over 45 years. The practice of sport walking showed significant differences in systolic blood pressure and diastolic blood pressure in men and women. By cons, changes in body weight and heart rate were no differences between the two groups.

\section{References}

Astrand, I., Astrand, P.O., Hallback, I., Kilbom, A. 1973. Reduction in maximal oxygen uptake with age. $J$. Appl. Physiol., 35: 649-54.

Blain, H., Vuillemin, A., Blain, A,. Jeandel, C. 2000. Les effets préventifs de l'activité physique chez les personnes âgées. Presse Med., 29: 1240-8.

Casa, D.J., Armstrong, L.E., Hillman, S.K., Montain, S.J., Reiff, R.V., Rich, B.S.E., Roberts, W.O., Stone, J.A. 2000. National Athletic trainers' Association position statement: fluid replacement for athletes. J. Athl. Traning, 35(2): 212-24. 
Halliwill, J.R., Buck, T.M., Lacewell, A.N., Romero, S.A. 2013. Postexercise hypo-tension and sustained postexercise vasodilatation: what happens after weexercise? Exp. Physiol., 98: 7-18.

Hecksteden, A., Grutters, T., Meyer, T. 2013. Association between postexercise hypotension and longterm training-induced blood pressure reduction: a pilot study. Clin. J. Sport Med., 23: 58-63.

Lakatta, E.G., Levy, D. 2003. Arterial and cardiac aging: major shareholders in cardiovascular disease enterprises: partII:theaging heart in health: links to heart disease. Circulation, 107: 346-354.doi:

10.1161/01.CIR.0000048893.62841. F7

MacDonald, J.R. 2002. Potential causes, mechanisms, and implications of postexercise hypotension. J. Hum. Hypertens, 16: 225-36.

Manon, R.C., Jeanne, V., Margot, V. 2008-2009. Quelles sont les conséquences de la pratique du sport sur l'organisme des individus, qu'ils soient des juniors ou des seniors? $1^{\text {ere }}$ 3 scientifique Lycee henri vincenot Louhans.

Matthias Wilhelm. 2011. Quelle quantité de sport renforce le coeur? Compterendu de l'atelier qui a eu lieu dans le cadre du $13^{\text {ème }}$ Colloque de formation continue du Collège de Médecine de Premier Recours (CMPR), le 16 juin 2011 à Lucerne.

Mitchell, J.H., Haskell, W.L., Raven, P.B. 1994. Classification of sports. J. Am. Coll. Cardiol., 24: 864-6.

Pescatello, L.S., Kulikowich, J.M. 2001. The aftereffects of dynamic exercise onambulatory blood pressure. Med. Sci. Sports Exerc., 33: 1855-61.

Rice, T., A.N.P., Gagnon, J., Leon, A.S., Skinner, J.S., et al. 2002. Heritability of heart rate and blood pressure response to exercise training in the HERITAGE Family Study. Med. Sci. Sports Exerc., 34: 972-979.

Thompson, P.D., Crouse, S.F., Goodpaster, B., Kelley, D., Moyna, N., Pescatello, L. 2001. The acute versus the chronic response to exercise. Med. Sci. Sports Exerc., 33 (suppl 6) : S438-S445.

Vigorito, C., Incalzi, R.A., Acanfora, D., Marchionni, N., Fattirolli, F., Gruppo Italiano di Cardiologia Riabilitativa e Preventiva. 2003. Raccomandazioni per la riabilitazione cardiovascolare del paziente molto anziano. (Recommendations for cardiovascular rehabilitation in the very elderly). Monaldi Arch. Chest Dis., 60: 25-39.

\section{How to cite this article:}

Moussouami Simplice Innocent, Bazaba Kayilou Jean Michel, Bouhika Eddie Janvier, Nsompi Florent, Nimi Fresnay Urgel, Mbemba François and Senga, P. 2016. Effect of Practice on the Hemodynamic profile of Elderly in Congo Brazzavillle. Int.J.Curr.Res.Aca.Rev.4(6): 1-6. doi: http://dx.doi.org/10.20546/ijcrar.2016.406.001 